\title{
Espacios de emancipación, propuestas indígenas desde el Ecuador
}

\author{
Silvia Soriano Hernández ${ }^{1}$
}

1 Doctora en Estudios Latinoamericanos por la Universidad Nacional Autónoma de México (UNAM). Investigadora del Centro de Investigaciones sobre América Latina y el Caribe y profesora del posgrado en Estudios Latinoamericanos en la UNAM. Correo electrónico: ssoriano@unam.mx. https://orcid.org/0000-0003-1917-1021

Fecha de recepción: 25/11/2019. Fecha de aceptación: 06/05/2020. 


\title{
Espacios de emancipación, propuestas indígenas desde el Ecuador
}

\section{RESUMEN}

La presencia indígena en Ecuador no se circunscribe a las manifestaciones en las calles. Desde lo local hasta lo nacional, los indios organizados han hecho propuestas que esperan incidan en las decisiones que se toman sin consultarles. Para reflexionar y valorar sus planteamientos, daré un breve recorrido por la imagen que expresan de la nación como representación, sin dejar de lado la cuestión del racismo. Me interesa cuestionar la idea de la modernidad como ajena a los indígenas, para considerar la democracia que caracteriza a nuestras sociedades como excluyente y cerrar con la militancia femenina para entender las opiniones formuladas por quienes se sienten parte fundamental de una estructura política como lo es la CONAIE.

Palabras clave: organización, democracia, racismo, género.

\section{Emancipatory spaces, indigenous proposals from Ecuador}

\begin{abstract}
The indigenous presence in Ecuador is not confined to street demonstrations. From local to national, organized Indians have made proposals that they hope will affect decisions that are taken without consulting them. In order to reflect and appreciate their approaches, I will make a brief tour of the image they express of the nation as a representation, without neglecting the question of racism. I am interested in questioning the idea of modernity as alien to indigenous people, to consider the democracy that characterizes our societies is exclusionary and, finally, approach female militancy to understand the opinions expressed by those who feel a fundamental part of a political structure such as the CONAIE.
\end{abstract}

Keywords: organization, democracy, racism, gender. 


\section{Preámbulo $^{2}$}

En octubre de 2019, las calles de Quito se llenaron de la colorida estampa de indígenas llegados de todas las regiones ecuatorianas. Protestaban por la imposición de medidas económicas que sin duda afectarían a grandes segmentos de la población y convocaban a otros sectores sociales a unírseles. No era la primera vez que esto sucedía, la Confederación de Nacionalidades Indígenas del Ecuador (CONAIE) ha organizado levantamientos desde 1990 y su presencia combativa llevó a caracterizarla como la "poderosa organización indígena». A fines del siglo pasado contribuyeron con sus movilizaciones a destituir a dos presidentes antipopulares y consiguieron colocarse como un sujeto político dispuesto a incidir en las decisiones que tomaba una élite. Para consolidarse como una estructura nacional, los indios fueron dando pasos firmes que no escaparon al divisionismo, la represión y los golpes orquestados desde diversos poderes. El objetivo de las siguientes líneas es destacar el significado que se otorga a la categoría de nación, para recuperar la propuesta indígena de la plurinacionalidad que invita a reflexionar sobre el tema de la exclusión y el racismo. Asimismo, me interesa considerar la cuestión de la democracia y la idea de la modernidad, que suele oponerse a las llamadas sociedades tradicionales como las comunidades indígenas, todos ellos aspectos relevantes para el debate actual. Cierro con una reflexión que mira a las mujeres dentro de las luchas amplias para comprender su deseo de militar en una estructura mixta que considere importante su visión y las expresiones de ella.

El tema de la nacionalidad no es nuevo, pero ha cobrado una significativa importancia política en varios grupos indígenas latinoamericanos, dado que estos han pugnado por ser reconocidos como una nación más al interior de sus países, a los que califican de uninacionales y, como consecuencia de ello, excluyentes. En Ecuador, fue el movimiento indígena aglutinado en la CNAIE el que lo demandó públicamente en 1990; tras sendas movilizaciones y discusiones abiertas, los indios de la confederación exigieron su reconocimiento como naciones, reclamando que se diera paso a designar al país como plurinacional, para que cada nación tuviese los mismos derechos y obligaciones ${ }^{3}$. En la asamblea constituyente celebrada en 1998, solo se aceptó que el Ecuador fuera considerado como pluricultural y multiétnico, enfatizando la diversidad propia del país y dejando de lado la reivindicación indígena (Soriano, 2016). Muchos de los argumentos para no consentir a la declaratoria

\footnotetext{
2 En este preámbulo sigo principalmente otro trabajo de mi autoría en el que analizo las propuestas de la CONAIE, El sentido de la disidencia. Indígenas y democracia en Ecuador. Agradezco al lector experto los comentarios, que fueron de gran valía.

3 Una reflexión interesante y crónica del día a día sobre el particular se puede consultar en Barrera (2001) además, por supuesto, de los diarios nacionales que dieron una amplia cobertura.
} 
de la plurinacionalidad giraron en torno al supuesto riesgo de abrir las puertas al separatismo, además, por supuesto, de no considerar importantes las propuestas emanadas desde los indios. La idea del rompimiento con la nación ecuatoriana, por otra parte, siempre ha sido desechada por la CONAIE. La que surgió fue una nueva constitución con viejos vicios.

Sin embargo, vientos diferentes comenzaron a soplar con el advenimiento a la presidencia de Rafael Correa, en 2007, quien nuevamente convocó a una asamblea constituyente, una década después de la anterior, y en esta ocasión el país fue reconocido como plurinacional. Grandes expectativas brotaron de amplios sectores populares, que consideraron que finalmente se les incluiría plenamente en el ser ecuatoriano. También se incorporó el concepto del buen vivir y se otorgaron derechos a la madre tierra en la nueva carta magna. Como es bien sabido, del reconocimiento a la redistribución suele existir un abismo y con el pasar de los años las posibilidades de que mejoraran las condiciones sociales de los indios no parecían cuajar.

\section{NaCión Y RACISMO}

Eldridge Cleaver (1970) formó parte de los movimientos por la lucha de la emancipación de los negros en Estados Unidos en la segunda mitad del siglo XX; escribió, en un artículo publicado en 1968, que era posible que ellos fuesen contemplados dentro de los Estados Unidos como una nación y, al poder verse así, esto es, como una fuerza englobada en una unidad nacional, era preciso actuar en consecuencia (p. 93). Según este autor, para entender la situación opresiva en que vivían (y viven) los negros en Estados Unidos, era necesario, de entrada, entender que la población afroamericana era un pueblo robado, sometido colonialmente dentro de una tierra robada (p. 87). Si no se comienza por ahí, agregaba Cleaver, cualquier análisis sobre el tema está condenado a dar soluciones erróneas. ¿Cómo enfrentarse a tal realidad? Para el líder negro, era necesario actuar como nación sometida que necesita emanciparse, afirmar su soberanía y exigir que esa soberanía sea reconocida por otras naciones del mundo (p. 92). «El Poder $\mathrm{Negro}^{4}$ — escribe Cleaver- le dice a los negros que es posible construir una organización nacional en la tierra de otros», "la tierra de otros» que no es reconocida como propia en la medida en que se les relega y carecen de una ciudadanía efectiva. Una minoría como tantas otras.

Floresmilo Simbaña, en su artículo Plurinacionalidad y derechos colectivos. El caso ecuatoriano (2005), hace un recorrido histórico del vivir de los indígenas en una

\footnotetext{
4 El término Black Power, como es bien sabido, surgió por aquella época y tuvo gran relevancia como categoría política.
} 
sociedad colonial, buscando hacer lo mismo que Cleaver, esto es, conocer el pasado histórico para entender la situación opresiva que los indígenas que pueblan Ecuador viven en el presente y saber, de tal modo, qué estrategias pueden usarse en la lucha de emancipación. Así, Simbaña comienza por decir que en los tiempos de los Inkas, a quienes no hablaban kichwa, la lengua oficial, se les conocía, peyorativamente, con el nombre de aucas (p. 198). Había pues, ya, en los pueblos de Abya Yala, sometimiento y discriminación anteriores a la conquista. Posteriormente, tras la inmensa masacre que constituyó la conquista, se fue pasando por diversos sistemas de dominación económica y social. El pensador peruano José Carlos Mariátegui señala la importancia del gamonalismo, donde los latifundistas y los propietarios agrarios jugaron un rol fundamental y donde, en palabras del peruano: «El indio alfabeto se transforma en un explotador de su propia raza porque se pone al servicio del gamonalismo» (Mariátegui, 2015, p. 39). En la República, dice, asciende al poder una clase cuya apropiación de las tierras de los indios fue determinante. El despojo de estas representó un golpe devastador para el indio en los distintos planos de su existencia (ético, social y espiritual). «En una raza de costumbre y de alma agrarias, como la raza indígena, este despojo ha constituido una causa de disolución material y moral. La tierra ha sido siempre toda la alegría del indio. El indio ha desposado la tierra. Siente que la vida viene de la tierra y vuelve a la tierra» (p. 48). La tierra es el elemento sobre el cual giran muchas de las reivindicaciones indígenas.

Continúa Simbaña diciendo que el indio, tras ser sometido, se recluyó en la comunidad — vista como un espacio social, vital y espacial - como medio de resistencia. En determinado momento del proceso histórico, las estructuras económico-sociales lo transformaron, al hacerlo pasar de un sujeto comunal en resistencia a un sujeto campesino en resistencia (2005, p. 200). Se trata pues, de un cambio en la visión de la identidad: los indios comenzaron a identificarse en sus posturas campesinas. Es así como los procesos económicos que alteran las relaciones de producción provocan cambios en las formas en que los distintos grupos se conciben a sí mismos, es decir, cambios en las identidades, en una reconfiguración que liga la vida diaria con los procesos a largo plazo.

Ya en los tiempos del Tawantinsuyo, el territorio era una compleja civilización agraria. En palabras de Mariátegui: «Los canales de irrigación de la sierra y de la costa, los andenes y terrazas de cultivo de los Andes, quedan como los mejores testimonios del grado de organización económica alcanzado por el Perú incaico. Su civilización se caracterizaba, en todos sus rasgos dominantes, como una civilización agraria» (2015, p. 59). Hay que enfatizar que para Mariátegui el Tawantinsuyo constituía una especie particular de comunismo agrario. La propiedad cultivable de la tierra era colectiva, así como el uso del agua. Las divisiones de las tierras las marcaban los ayllus, que estaban constituidos por conjuntos de familias empa- 
rentadas. El desarrollo de la economía dentro del Tawantinsuyo se daba, por así decirlo, de manera natural, respondiendo a leyes internas que estaban en correspondencia absoluta con un entorno preciso. Desde ese determinado ángulo es necesario observar el cambio económico y social que irrumpió con la conquista española. El despojo de las tierras queda marcado en las poblaciones que contaron con un conocimiento preciso del medio ambiente, y su recuperación forma parte del repertorio de lucha y resistencia en la región andina.

Mariátegui hace, pues, la distinción entre una economía orgánica y una cuyas bases son, en gran medida, artificiales, desapegadas del contexto preciso al que, sin una comprensión natural y profunda del entorno y de las leyes intrínsecas del territorio y sus habitantes, sobrexplota. «Una economía indígena, orgánica, nativa, se forma sola. Ella misma determina espontáneamente sus instituciones. Pero una economía colonial se establece sobre bases en parte artificiales y extranjeras, subordinadas al interés del colonizador» (Mariátegui, 2015, p. 61). Así entonces, los intereses del conquistador suelen estar en choque con el entorno y los habitantes a los que coloniza, provocando diversas catástrofes de diferente naturaleza. Es pues, como pensaba Cleaver a propósito de América del Norte, entender el contexto actual de los países andinos con una visión histórica, es decir, una perspectiva que considere al colonialismo como un proceso fundamental. Es imposible entender el racismo sin una visión histórica.

El racismo debe interpretarse como uno de los vectores de una estructura socioeconómica y psicológica. Para entender esto resulta esclarecedor el concepto de blanquitud propuesto por el filósofo ecuatoriano Bolívar Echeverría. El racismo contemporáneo, según la reflexión de este autor, requiere de vislumbrar la relación histórica "casual» entre el protestantismo inglés y el capitalismo. Dado que el gran desarrollo del capitalismo tuvo lugar en territorios con población mayoritariamente blanca y protestante, la identidad ética y religiosa del capitalismo, tomó como «visibilidad» la «blancura» racial de los protestantes ingleses blancos (Echeverría, 2011, p. 62). Hubo, pues, un vínculo profundo e inextricable entre la ética protestante y la modernidad capitalista, vínculo que, por decirlo así, se visibilizó en los cuerpos blancos. De allí que existan distintos estudios que profundizan en la relación entre la moral protestante y el espíritu capitalista. La ética del protestante «ahorrador» favoreció las posibilidades de la acumulación del capital.

Para alcanzar del todo el fenómeno, es preciso vislumbrar la distinción que el autor ecuatoriano hace entre blancura y blanquitud. La blancura se representa como el color blanco racial de la piel, mientras la segunda remite o invoca al espíritu o el aura que esos cuerpos adquieren. Es decir, la blanquitud es lo que se exige de la población, se le pide «tener blanquitud», tender hacia ella. En ese sentido tal categoría admite cierta flexibilidad, dado que se concibe también como un ideal hacia 
el cual hay que tender. Debajo de la blanquitud «flexible» siempre subyace una blancura amenazante y: «Basta con que el Estado capitalista entre en situaciones de recomposición de su soberanía y se vea obligado a reestructurar y redefinir la identidad nacional que imprime a las poblaciones sobre las que se asienta, para que la tesis de la blanquitud retorne al fundamentalismo y resucite a la blancura étnica como prueba indispensable de la obediencia al "espíritu del capitalismo", como señal de humanidad y modernidad» (Echeverría, 2011, p. 67) .

Imaginar un Estado plurinacional, tratando de incluir realmente la diversidad que contiene un país, estaría, por supuesto, en las antípodas de los Estados totalitarios (como la Alemania de Hitler) pero también sería un cambio radical con respecto a las «democracias» occidentales y de su, retomando dos términos empleados por Rivera (2010), «multiculturalismo oficial» o «multiculturalismo ornamental» (p. 58). Sobre este último aspecto la boliviana escribe: «Cooptación y mímesis, mímesis y cooptación, incorporación selectiva de ideas, selección certificadora de cuáles son más válidas para alimentar ese multiculturalismo de salón, despolitizado y cómodo, que permite acumular más caras exóticas en el living y dialogar por lo alto sobre futuras reformas públicas» (p. 68).

Aquí regreso a la propuesta de la CONAIE en el sentido de que lo que se desprende de lo plurinacional no remite solo a una declaración constitucional, es más radical, es de fondo y debe tocar lo social, lo político y lo cultural, por lo que lleva implícito un cambio del modelo económico, dado el claro agotamiento de las políticas neoliberales; una propuesta que conduzca a una mutación del Estado, una transformación esencial que lleve a la inclusión y resulte de un debate nacionaldel conjunto de la sociedad. Por tal razón, volviendo a Simbaña, no es posible

\footnotetext{
5 No sobra recordar cómo en la Alemania nazi, cuya aparición fue precedida de una fuerte crisis económica, la flexibilidad que alberga la blanquitud se ve relegada y muestra e impone la blancura étnica que subyace en esa exigencia, adoptándola como una norma inquebrantable. Por ello, para Echeverría, el racismo feroz en un régimen como el de la Alemania nazi, no es un mero capricho, sino que tiene «razones» históricas que lo impulsan. La visibilidad «palpable» que exigía el capitalismo que necesita encarnarse en determinado tipo de cuerpos excluye todo lo que se aleja del blanco europeo, como veíamos hace un momento. Surge la pregunta: ¡cómo explicar, entonces, el rechazo al judaísmo que fue característico de la Alemania nazi? La respuesta que da el pensador ecuatoriano es la siguiente. Dos razones, a su parecer, sostienen la actitud antisemita de los nazis. Por un lado, el movimiento nazi era profundamente demagógico y necesitaba hacerse pasar por un movimiento revolucionario que rompía con las sendas del capitalismo que tantos estragos estaba dejando en la población alemana, sobre todo en los sectores más desfavorecidos, como la clase obrera. Atacar a la comunidad judía hacía parecer que el movimiento nazi realmente estaba rompiendo con las estructuras sociales y económicas, dando la impresión de un espíritu radical y revolucionario. Por otro lado, complementando la intención anterior, retomar la tradición antisemita, que ya tenía una larga historia en Europa, y adoptar al judío como chivo expiatorio, permitiría con mayor facilidad desviar la atención de las élites plutocráticas y concentrar «los males» en el personaje del judío. El antisemitismo nazi era, pues, una estrategia política, apoyada en una coyuntura precisa, de crisis, a partir de la cual se impulsaba (Echeverría, 2011, p. 70).
} 
entender la plurinacionalidad dejando de lado la cotidianidad sociocultural o la realidad basada en las estructuras económicas. Para vislumbrar ambos aspectos es necesaria también la visión histórica. Esto debe remarcarse, en la medida en que esa mirada, al profundizar en el proceso histórico y en la actualidad geopolítica de cada contexto, permite una lectura de los mecanismos de poder coloniales impuestos desde el centro; en otras palabras, supone contextualizar el poder. Los indígenas organizados en la CONAIE, subraya el ecuatoriano, son doblemente explotados, debido a su condición social y étnica. Sin una batalla contra las desigualdades económicas propias de la explotación de ciertos sectores de la población a otros, la visión plurinacional carece de sustento. Por ello Simbaña añade que «sin una base económica sólida ninguna cultura puede sostenerse y menos desarrollarse. La burguesía pretende que las culturas indígenas se desarrollen por la pura gracia de la nueva Constitución Política del Ecuador y la sola voluntad de los mismos pueblos que viven en la más crónica de las miserias económicas y las desigualdades políticas» (Simbaña, 2005, pp. 204,206)

Ciertas pretensiones de autonomía sin una visión radical que abarque los distintos aspectos determinantes en la vida social, es decir, las relaciones entre la colectividad y el individuo, entre los sectores sociales y entre los grupos de poder, así como las relaciones de sometimiento dentro de las estructuras socioeconómicas, producto de un proceso histórico, caen en la trampa que Simbaña refiere cuando indica que se puede llegar "a cambiar un poco para no cambiar nada». Inclusive, tales pequeños cambios pueden resultar en un retroceso o al menos en un estancamiento de lo anhelado, que es, a fin de cuentas, la búsqueda de la emancipación humana y social. Simbaña concluye:

La demanda de reconocimientos de autonomías y derechos indígenas sin una definición clara y amplia que dé cuenta de la convivencia del derecho individual con el colectivo, de la libertad individual y los derechos culturales y colectivos; que dé un nuevo fundamento a la unidad nacional, más allá de meros enunciados, y postule propuestas políticas, económicas, socio-organizativas y culturales, puede resultar en consecuencias contrarias a las buscadas: reducir el proceso de la autonomía a aquello que en Norteamérica se denominan las reservaciones indígenas, o llevar a estancamientos o autolimitaciones del proceso (2005, p. 205).

Repito la frase de Simbaña que es clave en este análisis: «sin una base económica sólida ninguna cultura puede sostenerse y menos desarrollarse». Esta es la razón por la cual muchos grupos indígenas han ido desapareciendo: la pobreza, la migración, el desprecio, son aspectos a los que deben hacer frente cotidianamente. La pérdida de lenguas y grupos enteros es una tragedia que debe corregirse, el verdadero desarrollo de las culturas pasa no solo por su reconocimiento sino por su apropiación real de recursos económicos. 
Para cerrar este apartado adelanto la apreciación de una mujer indígena ecuatoriana que llegó a la dirigencia de su estructura social, en la que se reflejaba el racismo imperante y cotidiano en su país y la importancia que ella misma otorga al hecho de militar en una organización para comprender el sentido que confiere identidad, pertenencia y orgullo. Nina Pacari fue la primera mujer indígena canciller en el continente y ha dedicado muchos de sus esfuerzos a mejorar la condición de los indios. En una nota publicada en el diario El País, a propósito de una gira que Pacari realizaba en España en julio de 2017, se señala lo siguiente sobre ella y el constante racismo, así como la importancia que otorga a la unidad indígena para revitalizar su identidad:

En la capital de la ciudad, Quito, estudió durante los años setenta y comprendió que no estaba sola: eran muchos los universitarios de origen indígena que querían continuar en contacto con los movimientos sociales iniciados en sus comunidades. «No éramos líderes indígenas, sino altavoces de nuestros pueblos en la ciudad». La exclusión les acompańaba. "Si queríamos acceder a un restaurante debíamos llevar los libros en las manos para que vieran que, aunque éramos indígenas, éramos cultos». De lo contrario no les permitían la entrada. En esos años decidió cambiar para siempre su nombre: de María Estela Vega a Nina Pacari, como siempre le habían llamado en su casa, y que significa «luz del amanecer» en lengua kichwa. Como ella, muchos universitarios comenzaron a hacer de sus rasgos su principal identidad y del orgullo indígena el arma contra al rechazo ${ }^{6}$.

Como la misma Pacari reconoce, los derechos obtenidos a través de luchas y movilizaciones no se ven reflejados en la vida diaria de las comunidades, o volviendo a Simbaña, sin una base económica difícilmente se entienden y viven esos reconocimientos.

\section{2. ¿SOlO HAY UNA FORMA DE SER MODERNo?}

Según diversas posturas, la República constituye una continuación de la agresión colonial para los países latinoamericanos. La modernidad, no obstante, es más bien un «modelo» impuesto que corresponde al desarrollo económico y social de los Estados Unidos. Se trata de lo que el filósofo ecuatoriano Bolívar Echeverría llama la «modernidad americana». Según este autor la modernidad capitalista, proveniente de Europa (modernidad europea, católica en el sur europeo) encontró en Estados Unidos un terreno sumamente propicio para desarrollarse con pasos agigantados. La modernidad capitalista que se construyó en Norteamérica, sin embargo, al

6 https://elpais.com/elpais/2017/07/12/planeta_futuro/1499860136_832423.html 
encontrarse en un terreno y en una circunstancia específica, tiene rasgos propios distintos a los de la modernidad Europea.

Así, siguiendo a Echeverría, el contexto capitalista europeo conllevaba, dentro del mismo sistema capitalista, una autocrítica de tal sistema. Tal situación, pues, evitaba que el desarrollo del capitalismo tuviera el campo totalmente libre. El terreno de Estados Unidos, su naturaleza, aunada a la ideología protestante de los colonos provenientes de Inglaterra, resultó, como han estudiado diversos autores, sumamente fértil para el desarrollo del capitalismo. Ese tipo de capitalismo (de la modernidad "americana») se desenvolvió de tal modo que se extendió, en mayor o menor medida, por todo el mundo. Entonces, la modernidad europea capitalista, acabó "contagiada» por la modernidad «americana». La «lógica», voraz, de la modernidad americana se impuso y se impone alrededor del mundo.

¿Cuáles son las características que podemos ubicar en tal modernidad de tipo «americana»? El exterminio de los habitantes del territorio de lo que ahora es Estados Unidos es un signo de ese tipo específico de modernidad capitalista. Dentro de ese sistema no existe un conflicto fuerte con el pasado o con realidades premodernas que obstaculizaran el desarrollo del mercado capital. Tal tipo de modernidad, pues, contiene dentro de sí el motor que le permite desarrollarse y expandirse indefinidamente. Por eso se globaliza. Por eso se torna obligada. La democracia, en un sistema tal, está subyugada y reorientada por las necesidades del mercado dentro de la modernidad «americana». Los impulsos genuinamente democráticos de las sociedades, así, con su energía siempre latente, se ven ahogados una y otra vez por la expansión capitalista.

A propósito de la modernidad, es central recuperar la idea que expresa de la Rosa (2010) al afirmar no solo lo que hemos mencionado ya, sino además que las movilizaciones indígenas contemporáneas apuntan sus demandas no hacia una simple conservación de sus prácticas tradicionales para mantenerse alejados del mundo moderno y occidental, sino que "expresan el deseo de beneficiarse también de las ventajas que ofrece la modernidad, pero sin que ello signifique una asimilación sociocultural que les obligue a negar sus propias cosmovisiones» (p. 25).

Los movimientos sociales son ese impulso social de un sujeto colectivo que busca liberarse de un sistema que es por definición antidemocrático, es decir, un sistema que excluye la participación de la población en las decisiones fundamentales de cada sociedad. Retomamos la definición de movimientos sociales del boliviano Luis Tapia: «Los movimientos sociales son la forma y sujeto de reflexión conflictiva de las sociedades sobre sí mismas» (Tapia, 2008, p. 67). Las decisiones de ese sujeto colectivo implican una autoidentificación.

$\mathrm{Si}$, como vimos con Echeverría, formas premodernas o proyectos de modernidad alternativa (de autocrítica dentro del capitalismo) frenaron parcialmente o, mejor dicho, no permitieron que el capitalismo se desarrollara tan libremente en 
Europa, a diferencia de Estados Unidos (donde el exterminio de indios nativos dejó «campo libre»), cabe hacer la pregunta: en América Latina, donde habitan diversas poblaciones indígenas, con propuestas de «modernidades alternativas» (pensamos, por ejemplo, en la CONAIE ecuatoriana) o con rememoraciones de aspectos premodernos, ¿no encontraría la modernidad capitalista, también, un freno o una autocrítica dentro de sí que le impidiera desarrollarse y extenderse ilimitadamente?

Tal pregunta puede, inevitablemente, derivar en otras. ¿Qué otros frenos, o con qué otros elementos entra en conflicto la modernidad "americana»? Cualquier factor que obstaculice el avance ilimitado del sistema económico que impera está siempre, potencialmente, en vías de desaparición. Esto se debe a que, como dice el ecuatoriano Pablo Dávalos, «Para el capitalismo no debe haber territorios libres de relaciones mercantiles, así como no deben existir seres humanos fuera de la condición homo económicus» (Dávalos, 2011, p. 20). El homo económicus, para Dávalos, es un humano que concibe la vida según los dictados de la economía capitalista.

\section{3. ¿DÓNDE ENTRa La DEMOcraCia?}

En América Latina, los pueblos indígenas son enclaves de resistencia que tienen como proyecto, muchas veces, construir una modernidad alternativa, verdaderamente democrática, ya que durante siglos ellos han sido excluidos de la democracia moderna. Habría que, por decirlo así, democratizar a la actual democracia. Pero, antes, ¿cómo podemos entender lo que es una democracia? Según Bobbio (2001), una democracia se define por la dirección que toma el poder: «La distinción entre democracia y autocracia está basada en un criterio completamente diferente, a su vez en la observación de que el poder o asciende de abajo hacia a arriba o desciende de arriba hacia abajo» (p. 194). Por otro lado, según el mismo autor, se puede hacer la distinción entre democracia formal y democracia sustancial. La democracia ideal, que pertenece al futuro, debe de ser sustancial y formal a la vez. Lo formal implica ciertas normas legales y la igualdad jurídica. Lo sustancial, en cambio, es el contenido de estas normas e implica, necesariamente, la igualdad social y económica. Así, pues, hay aspectos de la sociedad que pueden haber alcanzado cierto grado de democratización, mientras otros se encuentran aún muy lejos de alcanzarla. Es muy conocida la sentencia de Bobbio que dice que la democracia se detiene en las puertas de las fábricas, sin acceso a ellas. La complejidad social, pues, desigual en diversos aspectos, acepta y rechaza, en distintos ámbitos sociales, los factores democratizadores. De nuevo Bobbio:

Una vez conquistado el derecho a la participación política, el ciudadano de las democracias más avanzadas se ha dado cuenta que la esfera política a su vez está incluida en una esfera de la sociedad en su conjunto, y que no hay decisión 
política que no esté condicionada o incluso determinada por lo que sucede en la sociedad civil, y por consiguiente una cosa es la democratización de la dirección política, lo que sucedió con la instauración de los parlamentos, y otra cosa es la democratización de la sociedad. De manera que bien puede darse un Estado democrático en una sociedad que la mayor parte de sus instituciones, la familia, la escuela, la empresa, los servicios públicos, no están gobernados democráticamente (2001, p. 219).

En los países de América Latina, por ejemplo, los pueblos indígenas suelen estar alejados de ciertos beneficios de la democracia que pueden favorecer a otros sectores sociales. Pablo Dávalos, en un análisis sobre los logros y los fracasos de la CONAIE en Ecuador (2006), deja claro que para alcanzar ciertos derechos de los cuales se está excluido, se debe de pelear por ellos en el terreno de la lucha de clases. Dicho de otro modo, la democracia debe conquistarse y modificarse. El economista ecuatoriano lo expresa en los siguientes términos: primero asume una actitud autocrítica y plantea que las prácticas políticas del movimiento indígena se fueron efectuando en clave liberal al considerar, entre otras cosas, que la Constitución Política se convertiría en el quid para cambiar la correlación de fuerzas pero «el texto no marca el contexto», por lo que no debe perderse el horizonte de la lucha de clases como el territorio de emancipación posible, además del contexto económico porque es asimismo «el territorio del ajuste estructural, de la reforma estructural, del Fondo Monetario, del Banco Mundial. Este terreno es económico porque ahí se define la conformación de las nuevas elites que manejan la economía mundial, que son las burguesías financieras. Esas burguesías que quieren desmantelar el Estado en función del interés propio. Quieren desmantelar un Estado que ya no les sirve». Vemos cómo hay cierta coincidencia entre el «texto» que no marca el «contexto» de Dávalos, y la distinción entre la democracia formal y la democracia sustancial de Bobbio. Pareciera, pues, que la democracia siempre se queda a mitad de camino, como si no lograra completarse del todo y tuviera una necesidad intrínseca de quedar inacabada. Esto tiene una razón, como afirma Quijano:

La democracia, bajo un manto burgués, va convirtiéndose en estos países y tanto más subdesarrolladas sus bases capitalistas y más profundo su sometimiento imperialista, en un juego de imposibilidades cuyo desemboque no puede ser sino - como lo muestran, cada vez más numerosos ejemplos- o la derrota de las masas acaudilladas por direcciones que solo buscan la afirmación de la democracia burguesa, o la imposición de la democracia con otro contenido de clase, como democracia de los trabajadores (Quijano, 2014, p. 546).

La democracia tiene un carácter de clase. Es común que en América Latina solemos contraponer las democracias a las dictaduras. Atribuimos a las primeras cierta libertad social y a las segundas la coacción o la limitación social. Nada como 
una rápida mirada a las movilizaciones que a fines de 2019 se dieron en Chile, Colombia, Haití o el mismo Ecuador, para cuestionar la separación entre coacción y libertad social. Según Bobbio, varios pensadores a lo largo de la historia se han opuesto a la democracia, como Hobbes, porque consideraban que el fin del Estado es la paz y el orden, mientras que otros, como Spinoza, fueron partidarios de la democracia, pues consideraban que la finalidad del Estado era la libertad del individuo (2001, p. 201).

Este dato nos lleva a hacer la distinción entre orden y seguridad, por un lado, y libertad por el otro. Henri Favre asegura que psicológicamente, por miedo a la incertidumbre, entre ambas opciones los humanos optan muchas veces por la primera: el orden y la seguridad. Así pues, el miedo a la inestabilidad social y económica, sobre todo durante los periodos de crisis, resulta favorable para los bloques de derecha o de extrema derecha y los regímenes dictatoriales. Basta constatar los resultados electorales de muchos países del planeta. Los nacionalismos exacerbados y el cierre de las fronteras van vinculados, muchas veces, con el temor proveniente de la inestabilidad económica o social. No obstante, volviendo a Echeverría, ya en la época del ultranacionalismo nazi, la postura nacionalista se enfrentaba a grandes obstáculos, a saber, la globalización que el capitalismo necesitaba para desenvolverse de forma más eficaz, más allá de las divisiones trazadas por las fronteras. Para determinada fase del capitalismo, el nacionalismo carece de eficacia. Así lo expresa Echeverría:

El capital comenzó a burlar la necesidad de desdoblarse en «muchos capitales» (Roman Rosdolsky); su acumulación parecía poder cumplirse sin el requisito de pasar por la mediación de la competencia entre muchos Estados apoyados en distintos proletariados nacionales dentro de un mercado mundial libre y neutral. La legitimidad de los Estados nacionales modernos de tipo europeo amenazaba con desvanecerse. La exacerbación de los nacionalismos en la primera mitad del siglo XX, lo mismo en Alemania que en Rusia, en Japón que en Estados Unidos, resultaba ser, no un signo de la actualidad de los pseudosujetos estatal-nacionales en calidad de encarnaciones de la sujetidad histórica económica del capital, sino precisamente un signo de lo contrario, de su obsolescencia y de su última, desesperada y violenta, resistencia a aceptarla (Echeverría, 2008, p. 41).

No obstante, incluso en el siglo XXI, con un impulso relacionado a la necesidad de orden en momentos críticos, los nacionalismos vuelven, exaltados por la desesperación social. En el mismo sentido, Favre considera que las democracias llevan, por así decirlo, el germen de la antidemocracia. Democráticamente, por medio de las urnas, la población alemana votó, por dar un ejemplo, por el partido encabezado por Hitler, esto es, por un mandatario totalmente antidemocrático ${ }^{7}$. Aquí nos

\footnotetext{
No está de más aquí la referencia a Jair Bolsonaro en Brasil.
} 
referimos, por supuesto, a la democracia propia del sistema electoral dentro de un contexto que precisa del método de elecciones para, al mismo tiempo que se afirma a sí mismo, reforzar su aire de libertad, o si se quiere, recrear la ilusión de ella.

Así pues, para Favre (2006), la democracia (electoral capitalista), además de las limitaciones de las que ya hablábamos, que le impiden ser del todo "democrática», es potencialmente autodestructiva. Por ello es que no es extraño encontrar que cuando los seres humanos se sienten amenazados por la incertidumbre, «se empeñan en darse un rey, dictador, tirano, duce o führer. El sacrificio de la libertad en beneficio de la seguridad es susceptible de darse según procedimientos democráticos» (p. 116).

La democracia moderna ofrece muchas caras. Otro aspecto trabajado por diversos autores es la capacidad que tiene la democracia para ejercer cierta coacción sobre la población, con métodos mucho más sofisticados y sutiles que aquellos de las dictaduras. El control se ejerce formando opiniones que validen las propuestas emanadas desde el poder gracias al papel que juegan, entre otros, los medios de comunicación, creando la ilusión de que se vive en un espacio pleno de libertad de expresión y de pensamiento.

Los expertos en legitimación, quienes trabajan para que parezca lícito lo que hacen quienes detentan el poder, son, fundamentalmente, las elites instruidas privilegiadas. Los periodistas, los académicos, profesores, los especialistas en relaciones públicas, todos estos grupos realizan una especie de tarea institucional: diseñar el consenso. Y, de nuevo, los más sofisticados lo reconocen. En las ciencias sociales académicas, por ejemplo, existe toda una tradición que explica la necesidad de una ingeniería del consenso democrático. Muy pocos critican esta idea. Entre ellos está un conocido sociólogo llamado Robert Dahl, quien ha seńalado algo que es a todas luces cierto: si tienes un sistema político en el que las opciones se definen desde una posición privilegiada, y eso es la democracia, entonces, no se le puede distinguir del totalitarismo. Es muy poco frecuente que se diga esto (Chomsky, 1999, p. 78).

¿Quiénes son los expertos de la legitimación de los que habla Chomsky? Cualquier sistema autoritario, dice el lingüista, dado que tiene la necesidad de controlar a la población, concibe a esta como un enemigo (p. 145). Las democracias no están exentas de esto. Un sistema autoritario administra a su población para mantener un control y un equilibrio social. Determinado equilibrio social favorece a cierto sector de la población en detrimento de otro. En ese sentido, un sistema autoritario, incluido el de las democracias (formales, retomando la distinción de Bobbio), protege en mayor o menor grado las desigualdades sociales.

Tal impulso devastador, recordemos, se relaciona con la modernidad de tipo «americana», que se constituyó en un terreno libre tras el exterminio en tal territorio 
de la gran mayoría de los habitantes de los pueblos originarios. De ahí que en Latinoamérica debamos considerar las propuestas que emanan desde colectivos indígenas como horizontes de emancipación que van más allá de los propios actores indios, pues atañen a muchos sectores excluidos de nuestras sociedades y, en última instancia, propugnan una reestructuración social que nos atañe a todos. La realidad de los pueblos indígenas es, por supuesto, heterogénea, y no está exenta de contradicciones internas. No obstante, desde su posición, y a través de la profundización del análisis del entorno de los pueblos indígenas, es posible ahondar en las objeciones hacia las democracias modernas basadas en la exclusión y, particularmente en el contexto latinoamericano, en la supresión, precisamente, de los pueblos indígenas. En este horizonte de expectativa, resulta interesante preguntarse qué tan importante es la participación femenina, aspecto que abordamos en el siguiente apartado.

\section{Mujeres en LA LUCHA}

Las organizaciones de mujeres han adquirido mayor relevancia dentro de los movimientos indígenas por la defensa de los territorios, invadidos, por así decirlo, en su mayoría, por compañías mineras transnacionales ${ }^{8}$. Ecuador no es la excepción, y como muestra mencionamos a la CONMIE (Concejo Nacional de Mujeres Indígenas del Ecuador), que surgió de la CONAIE (sobre la que hemos centrado este artículo) y fue constituida por Teresa Simbaña. La CONMIE se creó, como dice su fundadora, porque las organizaciones indígenas mixtas estaban dominadas por hombres y la participación de las mujeres se veía constantemente limitada. En un principio hubo incluso miembros de la CONAIE que se opusieron a la creación del grupo de mujeres (Simbaña, 2003). Algunos hombres empezaron a sentir cómo su dominio era cuestionado por una minoría dentro de una minoría: las mujeres indígenas. De acuerdo con Teresa Simbaña, uno de los objetivos principales de la CONMIE era otorgarle mayor dignidad y autoestima a las mujeres que se involucran en los movimientos sociales y que ven cómo su participación está limitada por el dominio masculino. La experiencia de Nely Shiguango, siendo particular no parece ser excepcional y retrata muy bien esta situación. Ella afirma:

\footnotetext{
8 Cito pocos ejemplos. Puede consultarse sobre Guatemala el artículo de Soriano y López donde afirman: «mujeres defensoras del cuerpo-territorio-tierra se integran a TZK'AT Red de sanadoras ancestrales del feminismo comunitario desde Iximulew, Guatemala, la cual tiene como uno de sus objetivos mantener redes de acompañamiento entre mujeres. Engarzan un profundo análisis político de la situación existente, tanto sobre la opresión y el despojo territorial como la interseccionalidad de opresiones que les afecta en la vida cotidiana y se manifiesta en la salud, la propia y la colectiva así como en la posibilidad de mantener el hilo comunitario ante la disgregación e individualidad promovida por el sistema económico prevaleciente» (2019, p. 46).
} 
Mi elección como dirigente de la organización me exigió que yo converse con los otros dirigentes y compañeros de las bases que eran hombres, eso disgustó mucho a mi marido y despertó sus celos. El día de mi posesión, mi marido, que había estado tomando, me pegó delante de toda la gente, reclamándome el que yo había estado conversando con otros hombres, sin entender que eso era parte de mi trabajo y no una actitud de loca. Yo me sentí humillada, pensé que la gente iba a perder la confianza en mí, especialmente los hombres. Por una parte me dio mucho dolor porque creí que podía perder a mi marido. Esta situación fue muy triste para mi persona en calidad de mujer y dirigente (Shiguango, 1998, p. 144).

Ella narra en su testimonio el camino que va de su infancia a su militancia y el conjunto de trabas sociales que fue sorteando para llegar a la dirigencia de una organización, desde su propia formación hasta el círculo cercano de su familia; y las múltiples resistencias para que ellas puedan participar en una organización. Su autoestima es humillada por su propio marido, al que no deseaba perder. Regreso a las palabras de Simbaña: «otorgarle mayor dignidad y autoestima a las mujeres» como primer paso para impulsar su participación en la lucha.

En Ecuador, como en otros país latinoamericanos, las luchas por la propiedad de la tierra en las comunidades indígenas se puede dividir en dos: primero la pugna por el reconocimiento de los territorios indígenas y, después, por el derecho de las mujeres, dentro de las mismas comunidades, a ser propietarias de tierras (Deere y León, 2002).

Es ilustrativo que muchas mujeres indígenas hayan decidido revisar los mitos cosmogónicos de sus propios pueblos. Dado que se concibe un vínculo estrecho entre la tierra, dadora de vida, y la mujer también como tal, existe una tradición muy fuerte que la ve como indisociable de su función materna, mujer y madre como binomio indisoluble. Ese podría no ser ningún problema; el conflicto surge cuando ciertas mujeres indígenas, que no estaban de acuerdo con considerar a la maternidad como una obligación que les exige dar vida, optaron por darle un giro a los valores tradicionales. Tales posturas, como es natural, trajeron consigo problemas internos en las comunidades, y se ha llegado incluso a que ciertos hombres acusen de etnocidas a aquellas que buscan una emancipación femenina dentro de los mismos pueblos indígenas ${ }^{9}$. Vemos cómo las desavenencias entre los diversos sectores se complejizan más: dentro de cada uno ya se encuentran conflictos internos, en este caso, de género. De allí la importante lucha que las mujeres deben dar para seguir siendo parte del movimiento pero demandado un reconocimiento a su propia experiencia dentro y fuera de la comunidad, como persona:

\footnotetext{
9 En el FONDO DOCUMENTAL/ NARRATIVAS DE MUJERES INDÍGENAS/ FLACSO/ ECUADOR se puede consultar un material muy valioso para conocer sobre estas mujeres.
} 
Teníamos que reconocer a la mujer que primero era una persona, por lo menos hablando de la autoestima, que era una persona que valía la pena, que ella era un ser humano, para levantar el autoestima, capacitar en derechos humanos, capacitar en derechos de la mujer, derechos colectivas para que sepa lo que consta aquí $[\ldots]$ y, últimamente, pues creo que durante estos cinco ańos hemos venido tratando de que las mujeres reconozcan que en el mundo indígena existe violencia. Ellas estaban acostumbradas a que era normal, pero no, no era normal, era un maltrato terrible desde su esposo, le maltrata la suegra, le maltratan todas las personas, si son empleadas domésticas los patrones le roban el seguro, no le pagan, le culpan de algo que se robó, nunca le pagan, entonces muy maltratada. Entonces ahora ellas con el conocimiento que tienen de la capacitación, ellas ya son personas, pueden reclamar algo, reclamar sus derechos. Entonces era muy importante que las mujeres un poco puedan reclamar sus derechos, puedan sentir que realmente son maltratadas en todos los aspectos. Entonces yo creo que ha sido muy formidable este tiempo (Simbańa, 2003, p. 3).

Confirmamos pues, cómo los distintos periodos históricos, con sus respectivas fases económicas, cambian la visión de determinados sectores sociales, en este caso el de las mujeres. No obstante, no se pueden perder de vista las grandes diferencias entre las mujeres pertenecientes a distintos sectores sociales. Hablamos principalmente del condicionamiento de clase y del condicionamiento étnico. Muchas indígenas mantuvieron la idea de que la disputa por la equidad de hombres y mujeres era asunto que solo competía a otro tipo de mujeres, las urbanas de clase media. Ellas, las indígenas, no debían disociarse de su esfera, de su pueblo, pues al actuar de tal forma, pensaban, terminarían por debilitar las luchas por la tierra y por el acceso a los recursos. Llegaron a la conclusión de que el pueblo debía combatir como un todo unificado (Deere y León, 2002, pp. 279-280) ${ }^{10}$. Aun algunas líderes indígenas afirmaron que el feminismo era un llamado al etnocidio, ya que la unidad del pueblo es esencial para la lucha y la búsqueda de los derechos. Muchos indígenas, miembros de distintas organizaciones, al considerar su disputa como una resistencia frente a la cultura dominante prefieren permanecer unidos y evitar los riegos de disolución que pueden implicar las luchas internas. No obstante, muchas mujeres pertenecientes a los movimientos sociales indígenas han reconocido que han padecido, dentro de las mismas organizaciones, discriminación de género. Veíamos hace un momento el caso de Teresa Simbaña y del movimiento englobado dentro de la CONMIE. Hay, como vemos, una gran diversidad de posturas

10 Para la experiencia de Nicaragua y Colombia, las autoras afirman: «En ambos países, el esfuerzo de las organizaciones de mujeres rurales, para fortalecer los derechos de la mujer a la tierra ha sido subordinada a la necesidad de solidaridad con las organizaciones y los sindicatos campesinos mixtos para apoyar la demanda general de reforma agraria en una situación política de confrontación» (Deere y León, 2002, p. 279). 
y visiones, muchas veces opuestas unas con otras, aun dentro de una esfera determinada. No sobra mencionar la importante trayectoria de muchas mujeres que en Ecuador han sabido dar la lucha como indígenas, pensando también en el significado de ser mujeres que tiene otras necesidades. Para cerrar me remito a Blanca Chancoso, militante de Ecuarunari (Ecuador Runacunapak Rikcharimui), filial de la CONAIE. A la pregunta sobre la participación política de los indígenas, ella reflexiona sobre la importancia de su organización, del proceso que ha seguido para conseguir y fortalecer una identidad de los indios, para afianzar un lugar en la sociedad política de Ecuador, así como sobre la situación particular de las mujeres. En este punto señala un innegable avance, pero también manifiesta críticas y dice que es cierto que ellas siempre han estado, pero más como acompańantes y sin reivindicación propia: «Desde las mujeres, no hemos estado, más bien acompañando y apoyando la lucha como pueblos, siempre así, pero no hemos hecho una cosa específica, digamos así, para nosotras las mujeres» (2003). Idea que sin duda abre nuevas interrogantes, no para desalentar, sino para mirar los espacios de liberación por los que bien vale apostar.

\section{REFLEXIÓN FINAL}

Los indígenas en América Latina tienen propuestas que abren nuevos horizontes de posibilidades. Aquí he retomado el caso de la CONAIE en Ecuador, para ilustrar las formas como podemos acercarnos a su organización, a sus movilizaciones y a las reflexiones que elaboran sobre una realidad que no atañe exclusivamente al universo indio, sino que apela a la sensibilidad de otros sectores de la población para buscar un nuevo rumbo, incluyente. Cuestionar la democracia que caracteriza a los países latinoamericanos es también un planteamiento que comparte la sociedad indígena organizada. El desprecio al diferente debe pasar por toda una nueva relación que posibilite debatir ese flagelo para construir un espacio diverso y plural de convivencia. Las mujeres indígenas deben ser vistas como parte integral de un proyecto esperanzador que vislumbre nuevas perspectivas. Su voz trasluce esas ideas, no dejemos de escucharlas.

\section{REFERENCIAS}

Barrera Guarderas, A. (2001). Acción colectiva y crisis politica. El movimiento indígena ecuatoriano en la década de los noventa. Quito: OSAL, Ciudad Centro de Investigaciones, Abya Yala.

Bobbio, N. (2001). Estado, gobierno y sociedad. CDMX: Fondo de Cultura Económica.

Chancoso, B. (2003). Fondo Documental/Narrativas de mujeres indígenas/FLACSO/ Ecuador. Entrevista a Blanca Chancoso realizada por Fernando García. Proyecto 
comparativo entre el movimiento indígena y el movimiento de mujeres en el Ecuador. Quito: FLACSO, fecha 25 de julio de 2003, no publicado.

Chomsky, N. (1999). Crónicas de la discrepancia. CDMX: La balsa de la Medusa.

Cleaver, E. (1970). Pantera negra. CDMX: Siglo XXI.

Dávalos, P. (2006). Ganamos pero perdimos: elementos para un balance del movimiento indigena en el Ecuador. CDMX: Centro de Estudios Andinos y Mesoamericanos.

Dávalos, P. (2011). La democracia disciplinaria. El proyecto posliberal para América Latina. Bogotá: Desde Abajo.

Deere, C. y León, M. (2002). Género, propiedad y empoderamiento: tierra, Estado y Marcado en América Latina. CDMX: PUEG-UNAM.

Echeverría, B. (2008). La modernidad americana. CDMX: Era.

Echeverría, B. (2011). Modernidad y blanquitud. CDMX: Era.

Favre, H. (2006). La democracia y sus fundamentalistas. Cuadernos americanos, 115, 111-117.

Mariátegui, J.C. (2015). Siete ensayos de interpretación de la realidad peruana. CDMX: Cien de Iberoamérica.

Quijano, A. (2014). Cuestiones y horizontes. Buenos Aires: CLACSO.

Rivera Cusicanqui, S. (2010). Ch'ixinakaz utxiwa. Una reflexión sobre prácticas y discursos descolonizadores. Buenos Aires: Tinta limón.

Rosa, de la, I. (2010). Movimientos indígenas contemporáneos en Ecuador y México. CDMX: CIALC-UNAM.

Shiguango, N. (1998). Historia de vida de Nely Shiguango. En Mujeres contracorriente: voces de lideres indigenas (pp. 135-147). Quito: CEPLAES.

Simbaña, F. (2005). Plurinacionalidad y derechos colectivos. El caso ecuatoriano. En P. Dávalos (comp.), Pueblos indígenas, estado y democracia (pp. 197-215). Buenos Aires: CLACSO.

Simbaña, T. (2003). Fondo Documental/Narrativas de mujeres indigenas/FLACSO/ Ecuador. Entrevista a Teresa Simbańa realizada por Georgina Méndez. Proyecto comparativo entre el movimiento indígena y el movimiento de mujeres en el Ecuador, dirigido por G. Herrera y F. García. Quito: FLACSO. Fecha: 23 de junio de 2003, no publicado.

Soriano Hernández, S. (2016). El sentido de la disidencia. Indígenas y democracia en Ecuador. CDMX: CIALC-UNAM.

Soriano Hernández, S. y López de la Vega, M. (2019). El testimonio de mujeres guatemaltecas como espacio donde la lucha germana. Politica y Cultura, 51, 31-54. https:// polcul.xoc.uam.mx/index.php/polcul/article/view/1375/1343

Tapia, L. (2008). Política salvaje. La Paz: CLACSO/Muela del Diablo Editores/Consejo Gráfico de Colección Sergio Vega. 